\title{
3 Research Suare \\ Catastrophic Health Expenditures and Its Inequality in Rural Poor Households in China
}

\section{Yihuan Wang}

Renmin University of China

\section{Chu Zhang}

Renmin University of China

Mengdi Guo ( $\sim$ guomengdi1228@163.com )

Zhejiang University

\section{Research}

Keywords: Rural poor households, Catastrophic health expenditure, Poverty, Inequality, China

Posted Date: June 23rd, 2021

DOl: https://doi.org/10.21203/rs.3.rs-627647/v1

License: (c) (1) This work is licensed under a Creative Commons Attribution 4.0 International License. Read Full License 


\section{Abstract}

Background: Catastrophic health expenditure (CHE) is an important indicator to measure health equity. Reducing risk of $\mathrm{CHE}$ and breaking vicious cycle between poverty and poor health are original intentions of medical security system design in various countries. This paper fulfills a research gap on $\mathrm{CHE}$ and its inequality in Chinese rural poor households.

Methods: Based on 2018 China Health and Retirement Longitudinal Study Data (CHARLS), Logit and Tobit regression models were used to analyze CHE incidence and intensity among rural poor households, and its socioeconomic inequality.

Results: The results showed that CHE incidence of rural poor households was $28.20 \%$, and the average intensity was 0.076 . For rural poor households, CHE incidence and intensity were higher than those in non-poor households at each given threshold from $20 \%$ to $60 \%$. Socioeconomic factors including household size, chronic disease status, disability status, health service utilization, whether to have older adults $\geq 65$ significantly associated with household $\mathrm{CHE}$.

Conclusions: Although China's social health insurance has almost achieved universal coverage, CHE incidence of rural poor households still remains high. A more refined health insurance policy with expanding current benefits packages, increasing reimbursement level is essential for protecting rural poor households from incurring CHE. Policy makers should also establish a new medical assistance system based on healthcare expenditure, which can effectively relieve medical economy burden of rural impoverished households.

\section{Background}

Poverty is a global issue that requires hard work of all governments. The relationship between poverty and health has been well documented [1,2]. To break vicious cycle between poverty and poor health, healthcare system becomes the fundamental part of protecting households from disease-associated financial catastrophe [3]. However, needed healthcare remains unavailable to millions of people owing to economic status, especially in poor and vulnerable groups [4, 5]. According to statistics from WHO, nearly 100 million people were pushed into poverty due to high out-of-pocket payments (OOP) [6].

OOP refer to the payments paid by individuals directly to health care providers [7]. Empirical evidence indicated that OOP was the most inefficient and inequitable means of healthcare financing, and prevented patients from seeking medical services [3]. CHE occurs when OOP consumed a huge part of a household's available income, thus forcing the household into risk of impoverishment $[8,9]$. Even modest healthcare bills could compel households into facing $\mathrm{CHE}$, when health financing mechanisms are unavailable or deficient. The possibility of $\mathrm{CHE}$ leading to household impoverishment raises equity concerns [10]. 
Different approaches were used to measure CHE: OOP account for $\geq 10 \%$ of total household expenditures [11-13], and OOP account for $\geq 40 \%$ of non-food household expenditures, which is proposed by WHO $[14,15]$. Previous studies suggested that a wide range of household characteristics associated with CHE. Logically, income is the most significant factor contributing to CHE inequality [16, 17]. Availability of health insurance can help reduce $\mathrm{CHE}$ incidence $[11,18]$. On the contrary, households with older adults $\geq 65$, children $\leq 5$, chronically ill members, disabled members [19], and those who use inpatient healthcare services are facing higher risk of CHE [20]. Compared to households with more members, households with fewer people are more likely to occur CHE [21]. There are also some other factors associating with CHE: gender, education level of household head, and healthcare service utilization [22].

On a global scale, the proportion of OOP in the world's population exceeding $10 \%$ of total household expenditure increased from $9.4 \%$ in 2000 to $12.7 \%$ in 2015 [23]. Previous studies indicated that $\mathrm{CHE}$ incidence (non-food threshold of 40\%) in France in 2011, Sweden in 2012, Germany in 2013 and Britain in 2014 was only $1.9 \%, 1.8 \%, 2.4 \%$ and $1.4 \%$, respectively, which were much lower than average level of $3 \%$ in OECD countries [24]. But for developing and underdeveloped countries, the situation is not so optimistic owing to lack of risk-share mechanism. In $2008,11.8 \%$ of Iran's population incurred CHE and was compelled into poverty [25]. China is no exception, previous study showed CHE incidence in 2015 was $16.5 \%$, and the households that actually incurred CHE spent $64 \%$ of their non-food consumption expenditure on medical expenses [26].

Therefore, to protect rural residents from large medical expenses, China has established New Rural Cooperative Medical Insurance (NRCMI) in 2003.In 2016, to further improve medical insurance level for rural residents, Chinese government decided to set up Urban and Rural Residents' Medical Insurance (URRMI) combined by both NRCMI and Urban Resident Basic Medical Insurance (URBMI).Despite realization of full coverage, the medical economy burden of Chinese residents was still high with OOP accounting for $28.61 \%$ in 2018[26].There was evidence showing that households insured by NRCMI almost had the same levels of CHE as those without any type of insurance[27-29].Moreover, several Chinese studies also reported that compare to urban households, rural households were still facing higher CHE risk, which associated with the fairness of healthcare services [30-32].

Numerous studies have conducted CHE studies on a specific country rather than vulnerable groups in the country. Owing to economic status, these vulnerable groups are still prevented from seeking needed and timely healthcare, and medical insurance systems haven't played an effective role in protecting them from occurring $\mathrm{CHE}$ [33]. However, few studies have examined incidence and determinant factors of $\mathrm{CHE}$ among rural impoverished households in China. As China has gradually realized the universal coverage of basic medical insurance system over the past three decades, relieving economy burden of rural poor residents' healthcare services and reducing inequality in medical insurance should gradually become the focus of new reform. Therefore, based on 2018 CHARLS data, this study aimed to analyze CHE incidence and intensity among rural poor households, and its socioeconomic inequality. Furthermore, our findings 
may contribute to improvement and adjustment of URRMI, thereby further relieve economy burden of healthcare and promote equity of healthcare system and services.

\section{Materials And Methods}

\section{Data Source}

Data were obtained from 2018 CHARLS, which is a national household survey collected by Peking University through multi-stage sampling method. The survey aims to collect national data of households and individuals $\geq 45$ in 28 provinces in China. The CHARLS questionnaire was designed according to international standards, including Health and Retirement Study (HRS) and etc. Therefore, the CHARLS survey data is internationally comparable and more valuable for assessing China's CHE incidence using WHO indicators. In 2018, the total number of households sampled was 11635, and the number of rural households was 8252. Based on the needs of CHE measurement, 591 households were excluded with missing variables, 7661 rural households were eventually included. According to China's poverty standard in 2018, which is 4833.4 CNY (1USD $=6.8792$ CNY, 2018) of rural residents' annual per capita net income, we obtain 3408 rural poor households and 4253 non-poor households.

\section{Indicators}

For the measurement of CHE incidence, we adopted the one proposed by WHO: when household's OOP is $\geq 40 \%$ of household's non-food household expenditure CTP (Capacity to pay), it is considered as catastrophic [34]. There are also some studies adopting another measurement that is, if OOP is $\geq 10 \%$ of total household expenditure [35]. In this study, we use WHO indicator due to the reason that deducting food expenditure can partly avoid measurement aviation.

The CHARLS questionnaire contents included general information on socio-economic and demographic households' characteristics, and healthcare utilization status. Our independent variables on each household comprised household size, per capita income of household, household with children $\leq 5$ years old, household with older adults $\geq 65$ years old, household including disabled members, household members with chronic disease, household members having sought outpatient care service during the past month, household members having sought inpatient care service during the past year, educational level of household head, and per capita security level of URRMI.

Based on 2018 CHARLS data, the variables of household size, per capita income and educational level of household head were set as continuous variables. Among which, we calculated per capita income of household by dividing the total household income by the number of household's members and taking the logarithm. Furthermore, according to the questionnaire and answer setting, household head's education level was divided into $0-5$ points as "illiterate $=0$; did not finish primary school $/$ home school $=1$; elementary school $=2$; middle school $=3$; high school/ vocational school $=4$; two-/three-year college/associate/bachelor's degree $=5$ ". Other variables including household with children $\leq 5$, household with older adults $\geq 65$,household with disabled member, household with chronically-ill 
member, household including member having sought outpatient care service during the past month and household including member having sought inpatient care service during the past year were set as dummy variables "yes $=1$, no $=0$ ". With regards to the variables of system and region, we calculated the proportion of per capita financing level of URRMI in per capita health care expenditure in each region (province, autonomous region, municipality directly under China's central government) to get the per capita security level of URRMI.

\section{Statistical Methods}

Stata 15.0 was used for descriptive analysis and measurement of CHE. The confidence level was set as $p<0.05$. To observe CHE incidence and intensity at each threshold based on $20 \%, 30 \%, 40 \%, 50 \%$, and $60 \%$ of CTP. Moreover, for the analysis of influencing factors of $\mathrm{CHE}$, we used the $40 \%$ threshold proposed by WHO.

\section{Results}

\section{Descriptive Statistics}

Descriptive statistics of characteristics of all rural households is concluded in Table 1. Among all rural households, the average household size was 2.762 and the mean household size of rural poor households (2.734) was a bit lower than that of non-poor ones (2.784). The proportion of children $\leq 5$ and older adults $\geq 65$ in rural poor and non-poor households were $10.04 \%, 7.81 \%$ and $58.66 \%, 35.13 \%$ respectively. Moreover, $23.21 \%$ of rural poor households reported having members who were disabled, and $60.80 \%$ of households with chronic diseases which were slightly higher than non-poor households(60.71\%). With regards to healthcare utilization, $17.49 \%$ of rural poor households reported to have members having sought outpatient care service during the past month in comparison with non-poor households $(15.89 \%)$. Almost one in five rural poor households $(19.31 \%)$ reported to have members having sought inpatient care service during the past year.

As for education background, most rural poor household heads reported having a poor education concentrated in illiteracy, primary school, and elementary school (1.197), which was a bit lower in comparison with household heads registered as non-poor households (1.714). With regards to control variable, per capita security level of URRMI was 0.403 in rural poor households, which was also a little lower than that in non-poor households (0.406). 
Table 1

Characteristics of Rural Poor and Non-poor Households

\begin{tabular}{|c|c|c|c|c|}
\hline \multirow[t]{2}{*}{ Characteristics } & Total & Rural poor & Rural non-poor & \multirow[t]{2}{*}{ p-value } \\
\hline & $(N=7661)$ & $(\mathrm{N}=3408)$ & $(N=4253)$ & \\
\hline \multicolumn{5}{|l|}{ Household variables } \\
\hline Household size & 2.762 & 2.734 & 2.784 & 0.150 \\
\hline \multicolumn{5}{|l|}{ Household with children $\leq 5$ years old } \\
\hline Yes & $8.80 \%(674)$ & $10.04 \%(342)$ & $7.81 \%(332)$ & \multirow[t]{2}{*}{0.001} \\
\hline No & $91.20 \%(6987)$ & $89.96 \%(3066)$ & $92.19 \%(3921)$ & \\
\hline \multicolumn{5}{|c|}{ Household with older adults $\geq 65$ years old } \\
\hline Yes & $45.59 \%(3493)$ & $58.66 \%(1999)$ & $35.13 \%(1494)$ & \multirow[t]{2}{*}{0.000} \\
\hline No & $54.41 \%(4168)$ & $41.34 \%(1409)$ & $64.87 \%(2759)$ & \\
\hline \multicolumn{5}{|l|}{ Household including disabled member } \\
\hline Yes & $20.52 \%(1572)$ & $23.21 \%(791)$ & $18.36 \%(781)$ & \multirow[t]{2}{*}{0.000} \\
\hline No & $79.48 \%(6089)$ & $76.79 \%(2617)$ & $81.64 \%(3472)$ & \\
\hline \multicolumn{5}{|c|}{ Household including member with chronic disease } \\
\hline Yes & $60.75 \%(4654)$ & $60.80 \%(2072)$ & $60.71 \%(2582)$ & \multirow[t]{2}{*}{0.937} \\
\hline No & $39.25 \%(3007)$ & $39.20 \%(1336)$ & $39.29 \%(1671)$ & \\
\hline Per capita income & 8.404 & 6.977 & 9.548 & 0.000 \\
\hline \multicolumn{5}{|c|}{ Household member having sought outpatient service during the past month } \\
\hline Yes & $16.60 \%(1272)$ & $17.49 \%(596)$ & $15.89 \%(676)$ & \multirow[t]{2}{*}{0.062} \\
\hline No & $83.40 \%(6389)$ & $82.51 \%(2812)$ & $84.11 \%(3577)$ & \\
\hline \multicolumn{5}{|c|}{ Household member having sought inpatient service during the past year } \\
\hline Yes & $16.67 \%(1277)$ & $19.31 \%(548)$ & $14.55 \%(619)$ & \multirow[t]{2}{*}{0.000} \\
\hline No & $83.33 \%(6384)$ & $80.69 \%(2750)$ & $85.45 \%(3634)$ & \\
\hline Educational level of household head & 1.484 & 1.197 & 1.714 & 0.000 \\
\hline \multicolumn{5}{|l|}{ Region variable } \\
\hline Per capita security level of URRMI & 0.405 & 0.403 & 0.406 & 0.112 \\
\hline
\end{tabular}




\section{CHE Incidence and Intensity in Rural Poor and Non-poor Households}

In Table 2, with threshold level increasing from 20-60\%, CHE incidence and intensity in both rural poor and non-poor households dropped remarkably. More importantly, at any given threshold, rural poor households were facing significantly higher headcount and overshoot than non-poor ones. At the lowest threshold of $20 \%$, rural poor households experienced the highest CHE incidence (45.89\%) and intensity (0.1486). Even at the highest $60 \%$ threshold, almost one in six $(16.52 \%)$ rural poor households had gone through CHE experience. By applying WHO standard of 40\% threshold, CHE incidence and intensity among rural poor households were $28.20 \%$ and 0.0756 respectively. Of all households sampled, rural nonpoor households demonstrated the greatest headcount (8.72\%) and overshoot (0.0014) at the highest $60 \%$ threshold.

Table 2

Incidence and Intensity of CHE

\begin{tabular}{|c|c|c|c|c|c|}
\hline & \multicolumn{5}{|c|}{ Catastrophic threshold } \\
\hline & $20 \%$ & $30 \%$ & $40 \%$ & $50 \%$ & $60 \%$ \\
\hline \multicolumn{6}{|l|}{ Total sample } \\
\hline Headcount & $38.58 \%$ & $29.09 \%$ & $22.13 \%$ & $16.56 \%$ & $12.19 \%$ \\
\hline Mean positive overshoot & 0.1145 & 0.0810 & 0.0554 & 0.0363 & 0.0219 \\
\hline \multicolumn{6}{|l|}{ Poverty sample } \\
\hline Headcount & $45.89 \%$ & $36.30 \%$ & $28.20 \%$ & $21.80 \%$ & $16.52 \%$ \\
\hline Mean positive overshoot & 0.1486 & 0.1078 & 0.0756 & 0.0508 & 0.0316 \\
\hline \multicolumn{6}{|l|}{ Non-poverty sample } \\
\hline Headcount & $32.73 \%$ & $23.32 \%$ & $17.28 \%$ & $12.37 \%$ & $8.72 \%$ \\
\hline Mean positive overshoot & 0.0874 & 0.0595 & 0.0393 & 0.0246 & 0.0014 \\
\hline \multicolumn{6}{|c|}{ Difference between poverty and non-poverty sample ( $T$ test) } \\
\hline Headcount & $0.1316^{\star \star \star}$ & $0.1298 * \star \star$ & $0.1092^{\star \star \star}$ & $0.0943^{\star \star \star}$ & $0.0780 * * *$ \\
\hline Mean positive overshoot & $0.0612^{\star \star \star}$ & $0.0483^{\star \star \star}$ & $0.0363^{\star \star \star}$ & $0.0262^{\star \star *}$ & $0.0176^{\star \star \star}$ \\
\hline
\end{tabular}

\section{Determinants of CHE Incidence}

Table 3 provides logistic regression results by using WHO indicator. It's worth noting that whether there were children $\leq 5$ in the household had no significant impact on CHE of rural impoverished households. 
Moreover, there was no significant correlation between household per-capita income and CHE among rural impoverished households, the increase of income couldn't reduce CHE. While for rural non-poor households, those with lower level of per capita income were more likely to face higher risk of $\mathrm{CHE}(\mathrm{OR}=$ $0.657 * \star * ; P<0.001)$. As for education background, there showed no significant correlation between household heads' educational level and CHE among rural poor households. Logically, CHE incidence of rural poor households was significantly higher in areas with lower security level of medical insurance, but our results didn't show the increase of per-capita security level of URRMI could reduce CHE incidence.

In addition, our results indicate there was significant correlation between household size and CHE among rural impoverished households, the increase of family member could reduce CHE $(\mathrm{OR}=0.810 * \star \star ; ~ P<$ 0.001). Whether there were older adults $\geq 65$ in the household also had significant impact on CHE of rural impoverished households as well $\left(\mathrm{OR}=1.643^{\star \star *} ; \mathrm{P}<0.001\right)$. In comparison with rural poor households without older adults $\geq 65$, the $\mathrm{CHE}$ incidence of those with older adults $\geq 65$ increased by $64.3 \%$. More importantly, households with disabled members were significantly more likely to incur CHE $\left(O R=1.275^{\star *}\right.$; $P<0.01)$. Both rural poor and non-poor households with chronic patient members were more vulnerable

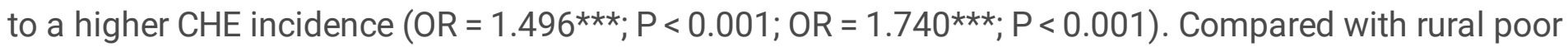
households without disabled or chronic patient members, CHE incidence of those with disabled or chronically ill members increased significantly by $27.5 \%$ and $49.6 \%$, and the average intensity increased by 0.014 and 0.027 respectively. Households with members who went to hospitals for outpatient care services during the past month or inpatient care services during the past year were much more vulnerable to $\mathrm{CHE}\left(\mathrm{OR}=1.460 * \star \star ; \mathrm{P}<0.001 ; \mathrm{OR}=2.198^{* \star *} ; \mathrm{P}<0.001\right)$. 
Table 3

Association between Factors and CHE in Rural Poor and Non-poor Households

\begin{tabular}{|c|c|c|c|c|}
\hline \multirow[t]{3}{*}{ Characteristics } & \multicolumn{2}{|c|}{ Incidence of $\mathrm{CHE}$ (logit) } & \multicolumn{2}{|c|}{ Intensity of $\mathrm{CHE}$ (tobit) } \\
\hline & Poor & Non-poor & Poor & Non-poor \\
\hline & Model 1 & Model 2 & Model 3 & Model 4 \\
\hline \multicolumn{5}{|l|}{ Fixed Effects } \\
\hline Intercept & $0.282^{\star \star}$ & $11.989^{\star \star \star}$ & $-0.254^{\star \star}$ & $0.441^{\star \star}$ \\
\hline \multicolumn{5}{|l|}{ Household variables } \\
\hline Household size & $0.810^{\star \star \star}$ & $0.771^{\star \star \star}$ & $-0.013^{\star \star \star}$ & $-0.009^{\star \star \star}$ \\
\hline Household with children $\leq 5$ & 1.007 & 1.052 & -0.001 & 0.005 \\
\hline Household with older adults $\geq 65$ & $1.643^{\star \star \star}$ & $1.903^{\star \star \star}$ & $0.031^{\star \star \star}$ & $0.024^{\star \star \star}$ \\
\hline Household with disabled member & $1.275^{\star \star}$ & 1.167 & $0.014^{*}$ & 0.006 \\
\hline Household with chronically-ill member & $1.496^{\star \star \star}$ & $1.740^{\star \star \star}$ & $0.027^{\star \star \star}$ & $0.018^{\star \star \star}$ \\
\hline Per capita income & 1.026 & $0.657^{\star \star \star}$ & 0.001 & $-0.018^{\star \star \star}$ \\
\hline Outpatient Utilization Status & $1.460^{\star \star \star}$ & $1.442^{\star *}$ & $0.019^{\star \star}$ & $0.010^{* *}$ \\
\hline Inpatient Utilization Status & $2.198^{\star \star \star}$ & $3.100^{\star \star \star}$ & $0.049^{\star \star \star}$ & $0.040^{\star \star \star}$ \\
\hline Educational level of household head & 0.959 & 0.947 & -0.003 & -0.002 \\
\hline \multicolumn{5}{|l|}{ Region variable } \\
\hline Per capita security level of URRMI & 0.725 & 0.494 & -0.017 & -0.012 \\
\hline \multicolumn{5}{|l|}{ Random Effects } \\
\hline Intercept variance & 0.066 & 0.033 & 0.003 & 0.001 \\
\hline Level 1 variance & 3.290 & 3.290 & 0.138 & 0.126 \\
\hline$-2 L L$ & 3756.63 & 3493.08 & 2977.18 & 2667.88 \\
\hline $\mathrm{N}$ & 3408 & 4253 & 3408 & 4253 \\
\hline
\end{tabular}

\section{Income-related inequality of $\mathrm{CHE}$}

Taking into account of the opportunity cost differences between the poor and the rich, we measured income-related inequality of CHE. With higher threshold level from $20-60 \%$, CHE incidence and intensity 
tended to decrease. The results in Table 5 indicated that rural poor households were much more vulnerable to CHE. More importantly, given a fixed threshold level, rural poor households were more likely to experience $\mathrm{CHE}$ than non-poor ones.

Table 4

Concentration Indexes of CHE in Poor and Non-poor Households

\begin{tabular}{|llllll|}
\hline \multicolumn{5}{c}{ Catastrophic threshold } \\
\cline { 2 - 6 } & $\mathbf{2 0 \%}$ & $\mathbf{3 0 \%}$ & $\mathbf{4 0 \%}$ & $\mathbf{5 0 \%}$ & $\mathbf{6 0 \%}$ \\
\hline Total sample & & & & & \\
\hline Incidence & -0.1050 & -0.1394 & -0.1548 & -0.1782 & -0.2035 \\
\hline Intensity & -0.1663 & -0.1857 & -0.2028 & -0.2232 & -0.2461 \\
\hline Rural poor sample & & & & & \\
\hline Incidence & 0.0163 & 0.0123 & 0.0018 & -0.0151 & -0.0204 \\
\hline Intensity & -0.0074 & -0.0150 & -0.0240 & -0.0336 & -0.0411 \\
\hline Rural non-poor sample & & & & & \\
\hline Incidence & -0.0939 & -0.1310 & -0.1390 & -0.1461 & -0.1820 \\
\hline Intensity & -0.1382 & -0.1518 & -0.1583 & -0.1686 & -0.1778 \\
\hline Note: ${ }^{*} p<0.05,{ }^{* \star} p<0.01,{ }^{* \star} p<0.001$ & & & \\
\hline
\end{tabular}

\section{Decomposition of CHE inequality in rural poor households}

In Table 5, the majority of the observed inequalities in CHE incidence of rural impoverished households can be attributed to household per capita income (53.50\%), having older adults $\geq 65(28.73 \%)$ and inpatient utilization status of household members (8.87\%). The total contribution percentage was $100 \%$.

In Table 6, the main positive contribution to inequality in intensity in rural impoverished households was associated with household per capita income $(57.16 \%)$, having older adults $\geq 65$ (26.63\%), inpatient utilization status of household members (8.15\%). The total contribution percentage was also $100 \%$. Some inpatient and outpatient services played a positive role in CHE inequality, which indicated that healthcare service utilization aggravated CHE inequality among rural impoverished households [36]. 
Table 5

Decomposition of Concentration Index of CHE Incidence (at a non-food expenditure threshold of 40\%)

\begin{tabular}{|c|c|c|c|c|}
\hline Characteristics & Elasticity & $\begin{array}{l}\text { Concentration } \\
\text { index }(\mathrm{Cl})\end{array}$ & $\begin{array}{l}\text { Contribution } \\
\text { to } \mathrm{Cl}\end{array}$ & $\begin{array}{l}\text { Contribution to } \\
\mathrm{Cl} \%\end{array}$ \\
\hline \multicolumn{5}{|l|}{ Household variables } \\
\hline Household size & -0.4066 & -0.0061 & 0.0025 & -0.0230 \\
\hline Household with children $\leq 5$ & 0.0047 & -0.1369 & -0.0006 & 0.0060 \\
\hline $\begin{array}{l}\text { Household with older adults } \geq \\
65\end{array}$ & 0.2079 & -0.1489 & -0.0310 & 0.2873 \\
\hline $\begin{array}{l}\text { Household with disabled } \\
\text { member }\end{array}$ & 0.0294 & -0.0878 & -0.0026 & 0.0240 \\
\hline $\begin{array}{l}\text { Household with chronically-ill } \\
\text { member }\end{array}$ & 0.1934 & -0.0005 & -0.0001 & 0.0009 \\
\hline Per capita income & -0.5336 & 0.1080 & -0.0576 & 0.5350 \\
\hline Outpatient Utilization Status & 0.0421 & -0.0347 & -0.0015 & 0.0135 \\
\hline Inpatient Utilization Status & 0.1086 & -0.0880 & -0.0096 & 0.0887 \\
\hline $\begin{array}{l}\text { Educational level of household } \\
\text { head }\end{array}$ & -0.0783 & 0.0817 & -0.0064 & 0.0594 \\
\hline \multicolumn{5}{|l|}{ Region variable } \\
\hline $\begin{array}{l}\text { Per capita security level of } \\
\text { URRMI }\end{array}$ & -0.2370 & 0.0038 & -0.0009 & 0.0083 \\
\hline
\end{tabular}


Table 6

Decomposition of Concentration Index of Intensity (at a non-food expenditure threshold of 40\%)

\begin{tabular}{|c|c|c|c|}
\hline Characteristics & Elasticity & $\begin{array}{l}\text { Concentration } \\
\text { index (Cl) }\end{array}$ & $\begin{array}{l}\text { Contribution } \\
\text { to } \mathrm{Cl}\end{array}$ \\
\hline
\end{tabular}

\section{Household variables}

\begin{tabular}{|c|c|c|c|c|}
\hline Household size & -0.5020 & -0.0061 & 0.0031 & -0.0212 \\
\hline Household with children $\leq 5$ & 0.0067 & -0.1369 & -0.0009 & 0.0064 \\
\hline $\begin{array}{l}\text { Household with older adults } \geq \\
65\end{array}$ & 0.2583 & -0.1489 & -0.0385 & 0.2663 \\
\hline $\begin{array}{l}\text { Household with disabled } \\
\text { member }\end{array}$ & 0.0373 & -0.0878 & -0.0033 & 0.0227 \\
\hline $\begin{array}{l}\text { Household with chronically-ill } \\
\text { member }\end{array}$ & 0.2392 & -0.0005 & -0.0001 & 0.0008 \\
\hline Per capita income & -0.7642 & 0.1080 & -0.0825 & 0.5716 \\
\hline Outpatient Utilization Status & 0.0416 & -0.0347 & -0.0014 & 0.0100 \\
\hline Inpatient Utilization Status & 0.1338 & -0.0880 & -0.0118 & 0.0815 \\
\hline $\begin{array}{l}\text { Educational level of household } \\
\text { head }\end{array}$ & -0.0990 & 0.0817 & -0.0081 & 0.0560 \\
\hline \multicolumn{5}{|l|}{ Region variable } \\
\hline $\begin{array}{l}\text { Per capita security level of } \\
\text { URRMI }\end{array}$ & -0.2281 & 0.0038 & -0.0009 & 0.0060 \\
\hline
\end{tabular}

\section{Discussion}

The urban-rural dual economic and social structure in China cannot be ignored. The relatively low income and lack of health care resources in rural regions make rural poor residents more vulnerable to the risk of CHE. This study used a national data from CHARLES to analyze extent, determinant factors and inequality of $\mathrm{CHE}$ among poor households. To the best of our knowledge, it is the first study to focus on these vulnerable groups and fulfills a research gap on Chinese rural poor households.

Previous studies have shown that the proportion of rural households incurring CHE (26.44\%) was still considerably higher than that of urban households (12.6\%) [26]. By applying WHO method, our results showed that CHE incidence and intensity of rural poor households in China were $28.20 \%$ and 0.076 respectively, much higher than those of non-poor households $(17.28 \%, 0.039)$. The difference means that there was inequity between rural impoverished households and non-impoverished ones in terms of medical insurance risk sharing mechanism and healthcare services, OOP of poor households is still high. 
Reducing risk of $\mathrm{CHE}$ and breaking vicious cycle between poverty and poor health are original intentions of medical security system design in China [37]. In this study, our findings found that, although existing health insurance schemes did provide certain financial protection for rural impoverished households, this protection was insufficient to some extent. In China, URRMI failed to effectively reduce the risk of CHE incurring in these poor households. As demonstrated in earlier studies, their results have also shown that the health insurance system didn't play an effective role in mitigating the risk of CHE [38]. Therefore, for rural poor households, URRMI alone is not enough to effectively relieve poor households' medical economy burden, multiple health insurance policies must work at the same time, such as medical assistance policies and major disease insurance scheme, thereby protecting these vulnerable groups from incurring $\mathrm{CHE}$.

It is noteworthy that our study showed that households with children $\leq 5$ were not at higher risk of CHE. Previous studies have shown that households with children $\leq 5$ and older adults $\geq 65$ tend to have higher incidence of $\mathrm{CHE}$ [28], while, some study implied that the impact of children $\leq 5$ was not significant [17]. With the continuous progress of medical technology and the comprehensive development of China's children's disease prevention and healthcare work such as free vaccinations for newborns, the probability of children $\leq 5$ suffering from major diseases is much lower, and the state also gives subsidies for treatment costs, which will greatly reduce medical economy burden of families. Moreover, previous study showed that there were some older adults in rural poor households who didn't go to hospital for treatment due to economic reasons [29], which can avoid the occurrence of CHE. To some extent, our results implied that the above phenomena may exist, which needs to be taken into serious consideration by our policymakers [39]. Interestingly, this study also revealed that per-capita income of households appeared to have no significant association on CHE of rural poor households. However, for non-impoverished households in rural regions, per-capita income was a significant factor associated with $\mathrm{CHE}$.

In consistence with previous studies, large household size could protect rural poor households against $\mathrm{CHE}$, and the probability of $\mathrm{CEH}$ risk would decrease as the number of family members increase [12]. Additionally, households with disabled members, chronically ill members were more likely to suffer from $\mathrm{CHE}$, similar with other published studies [13]. The reason is that chronic diseases or disabilities not only limit a person's productive work ability, thus limiting household's economic output, but also cause high medical expenditure [39-41]. Therefore, expanding reimbursement catalogue of chronic diseases and disabilities in outpatient care services or enhancing reimbursement level of inpatient care services can play an effective role in protecting these vulnerable households from high OOP and financial health crisis [13].

This study also revealed that households with members who have sought for outpatient care services during the past month or inpatient care services during the past year were more vulnerable to a higher $\mathrm{CHE}$ incidence. Moreover, from a social welfare perspective, $\mathrm{CHE}$ were worse than it appeared by simply looking at part of the population that exceeds the threshold, because this overlooked the fact that the poor tend to exceed this threshold [28]. In addition, household having older adults $\geq 65$ also significantly associated with $\mathrm{CHE}$ and was a major positive contributor to $\mathrm{CHE}$ inequality. Therefore, as China's aging 
population aggravates, the government must adjust healthcare policy concerned with older adults in order to decrease CHE inequality.

Some limitations of this study must be acknowledged. (1) 2018 CHARLS data used in the research is a cross-sectional data, which cannot analyze the dynamic changes of the determinant factors of $\mathrm{CHE}$ among rural impoverished households, nor solve the problem caused by possible missing variables. (2) Since there were rural residents not seeking for medical treatment due to insufficient income and lack of healthcare resources, CHE in rural impoverish households may be underestimated to a certain extent. (3) The measurement of OOP did not include indirect expenditure for seeking medical care such as income loss due to illness, accommodation and transportation, which may lead to underestimation of household healthcare expenditure and $\mathrm{CHE}$ incidence.

\section{Conclusion}

The relatively lower income level and lack of health care resources in rural China make impoverished households more vulnerable to the risk of CHE. Rural impoverished households are facing higher incidence of $\mathrm{CHE}(28.20 \%)$ and intensity (0.076). With little income left after necessary expenditure, it is highly possible for them to forgo needed health care, which raises an inequity question as to what happens to the poorest of the poor who are unable to afford health care. Moreover, determinants of CHE include household size, having older adults $\geq 65$, having disabled members, having chronic patient members, having members seeking outpatient or inpatient service. There are also significant differences between the regression analysis of rural impoverished households and non-impoverished households, indicating inequity in $\mathrm{CHE}$ exists among them. Therefore, in order to reduce $\mathrm{CHE}$ incidence among rural impoverished households, solutions should not be limited to improving employment opportunities and public health care for the poor. The results of this study call for a more equitable, affordable and inclusive URRMI mechanism with expanding current benefits packages and increasing reimbursement level. Policy makers should also establish a new medical assistance system based on healthcare expenditure, which can effectively prevent CHE from occurring in rural impoverished households.

\section{Declarations}

Ethical approval: Ethical approval for all the CHARLS waves was granted from the Institutional Review Board at Peking University. The IRB approval number for the main household survey, including anthropometrics, is IRB00001052-11015; the IRB approval number for biomarker collection, was IRB00001052-11014. During the fieldwork, each respondent who agreed to participate in the survey was asked to sign two copies of the informed consent, and one copy was kept in the CHARLS office, which was also scanned and saved in PDF format. Four separate consents were obtained: one for the main fieldwork, one for the non-blood biomarkers and one for the taking of the blood samples, and another for storage of blood for future analyses.

Consent for publication: Not applicable. 
Availability of data and materials: The datasets generated and/or analysed during the current study are available in the [CHARLS] repository, [http://www. charls.pku.edu.cn]

Competing interests: The authors declare that they have no competing interests.

Funding: This research was funded by Ministry of Finance of the People's Republic of China (No. 2020K20071). The funding bodies were not involved in the design of the study, or data collection, analysis, and interpretation or in writing the manuscript.

Author contributions: Conceptualization, C.Z. and Y.W.; methodology, C.Z.; validation, C.Z., M.G. and Y.W.; formal analysis, C.Z. and Y.W.; investigation, C.Z. and Y.W.; data curation, C.Z.; writing-original draft preparation, C.Z. and Y.W.; writing-review and editing, C.Z., M.G. and Y.W.; supervision, M.G.; All authors read and approved the final manuscript.

Acknowledgments: We would like to acknowledge China Health and Retirement Longitudinal Study for their cooperation. We would also like to thank all study participants for their time to be interviewed.

\section{References}

1. Walters, Sarah, Suhrcke, Marc. Socioeconomic inequalities in health and health care access in central and eastern Europe and the CIS: a review of the recent literature: Morgan Kaufmann Publishers Inc.; 1990.

2. World H, Organization O. DAC Guidelines and Reference Series Poverty and Health. http://whqlibdocwhoint/publications/2003/9241542366pdf.

3. Hill K. The World Health Report 2000: Health Systems: Improving Performance. Population and Development Review. 2001;27(2).

4. Ke X, Evans DB, Carrin G, Aguilar-Rivera AM, Musgrove P, Evans T. Protecting Households From Catastrophic Health Spending. Health Affairs. 2007;26(4):972-83.

5. Shahrawat R, Rao KD. Insured yet vulnerable: out-of-pocket payments and India's poor. Health Policy and Planning. 2012;27(3):213-21.

6. World Health 0 . World health report, 2010: health systems financing, the path to universal coverage. Web server without geographic relation, Web server without geographic relation (org): WHO; 2010.

7. World Health 0 . Validity and comparability of out-of-pocket health expenditure from household surveys: a review of the literature and current survey instruments. Web server without geographic relation, Web server without geographic relation (org): World Health Organization; 2011.

8. Ke X, Evans DB, Kawabata K, Zeramdini R, Klavus J, Murray CJL. Chapter 42: UNDERSTANDING HOUSEHOLD CATASTROPHIC HEALTH EXPENDITURES: A MULTI-COUNTRY ANALYSIS. World Health Organization; 2003. p. 565-72.

9. Buigut S, Ettarh R, Amendah DD. Catastrophic health expenditure and its determinants in Kenya slum communities. International Journal for Equity in Health. 2015;14(1). 
10. Adam W, Eddy van D. Catastrophe and impoverishment in paying for health care: with applications to Vietnam 1993-1998. Health Economics. 2003(11):921.

11. Galárraga O, Sosa-Rubí SG, Salinas-Rodríguez A, Sesma-Vázquez S. Health insurance for the poor: impact on catastrophic and out-of-pocket health expenditures in Mexico. 2010.

12. O O'Donnell EVD, A Rannan-Eliya, CG Somanathan, E Doorslaer, SV Rannan-Eliya. Explaining the incidence of catastrophic payments for health care: comparative evidence from Asia. REQUITAL Working Paper No5. 2005.

13. Bredenkamp C, Mendola M, Gragnolati M. Catastrophic and impoverishing effects of health expenditure: new evidence from the Western Balkans. Health Policy and Planning. 2011;26(4):34956.

14. Obinna $\mathrm{O}, \mathrm{Kara} \mathrm{H}$, Benjamin $\mathrm{U}$. Examining inequities in incidence of catastrophic health expenditures on different healthcare services and health facilities in Nigeria. PLoS ONE. 2012;7(7):e40811-e.

15. Hoang Van M, Nguyen Thi Kim P, Saksena P, James CD, Ke XU, Health System Reform in A. Financial burden of household out-of pocket health expenditure in Viet Nam: Findings from the National Living Standard Survey 2002-2010. Kidlington: Elsevier; 2013. p. 258-63.

16. Moradi T, Naghdi S, Brown H, Ghiasvand H, Mobinizadeh M. Decomposing inequality in financial protection situation in Iran after implementing the health reform plan: What does the evidence show based on national survey of households' budget? International Journal of Health Planning and Management. 2018;33(3):652-61.

17. Jiao M, Ning N, Gao L, Zhang Z, Wu Q, Hao Y, et al. The impact of different benefit packages of Medical Financial Assistance Scheme on health service utilization of poor population in Rural China. BMC Health Services Research. 2010;10(1):170-

18. Lara Jeannette Liliana A, Gómez Fernando R. Determining factors of catastrophic health spending in Bogota, Colombia. International Journal of Health Care Finance and Economics. 2011;11(2):83-100.

19. Li Y, Wu Q, Xu L, Legge D, Hao Y, Gao L, et al. Factors affecting catastrophic health expenditure and impoverishment from medical expenses in China: policy implications of universal health insurance / Facteurs affectant les dépenses de santé catastrophiques et l'appauvrissement dû aux dépenses médicales en Chine: implications des politiques de l'assurance de santé universelle / Factores que afectan a los gastos sanitarios catastróficos y el empobrecimiento provocado por los gastos médicos en China: repercusiones políticas de un seguro sanitario universal. Bulletin of the World Health Organization. 2012;90(9):664-71.

20. Limwattananon S, Tangcharoensathien V, Prakongsai P. Catastrophic and poverty impacts of health payments: Results from national household surveys in Thailand. Bulletin of the World Health Organization. 2007;85(8):600-6.

21. Liu L, Zhao L, Li N, Zhang X. Empirical analysis of the status and influencing factors of catastrophic health expenditure of migrant workers in Western China. International Journal of Environmental Research and Public Health. 2019;16(5). 
22. Li A, Shi Y, Yang X, Wang Z. Effect of critical illness insurance on household catastrophic health expenditure: The latest evidence from the national health service survey in China. International Journal of Environmental Research and Public Health. 2019;16(24).

23. World Health $\mathrm{O}$, International Bank for R, Development. Global monitoring report on financial protection in health 2019. Web server without geographic relation, Web server without geographic relation (org): World Health Organization; 2020.

24. Oecd, Ocde. Health at a Glance 2019: OECD Indicators: Éditions OCDE / OECD Publishing; 2019.

25. Kavosi Z, Rashidian A, Pourreza A, Majdzadeh R, Pourmalek F, Hosseinpour AR, et al. Inequality in household catastrophic health care expenditure in a low-income society of Iran. Health Policy and Planning. 2012;27(7):613-23.

26. Xu Wenjuan, Chu Fuling. " Study on Catastrophic Health Expenditure Level and Influencing Factors --An Analysis Based on CHARLS." Social Security Studies(in Chinese). 2018;5:64-72.

27. Wagstaff A, Lindelow M. Can insurance increase financial risk ? The curious case of health insurance in China. The World Bank; 2005.

28. Li Y, Wu Q, Liu C, Kang Z, Xie X, Yin H, et al. Catastrophic Health Expenditure and Rural Household Impoverishment in China: What Role Does the New Cooperative Health Insurance Scheme Play? PLoS ONE. 2014;9(4):1-9.

29. Huang Shusheng, and Yin Aitian. Household catastrophic health expenditure and its influencing factors among rural residents in Shandong province. Chin J Public Health(in Chinese). 2018;34(09):1221-3.

30. Yang Hongyan, Huang Meng. The rural-urban difference and distribution-sensitive of Catastrophic Health Expenditure. Chinese Journal of Health Policy(in Chinese) . 2018;11(07):24-9.

31. Gao Mengting, Yang Juan, Yan Hong, Li Shiyue. Catastrophic health expenditure of rural households and its influencing factors in Hubei Province. Chinese Journal of Health Statistics(in Chinese). 2016;33(06):1008-9+13.

32. Li Ye, Wu Qunhong, Gao Lijun. Analysis on causes of catastrophic health expenditure in rural China from perspective of system analysis. Chinese Journal of Health Policy(in Chinese). 2012;5(11):55-9.

33. Yip W, Hsiao WC. Non-evidence-based policy: How effective is China's new cooperative medical scheme in reducing medical impoverishment? Social Science and Medicine. 2009;68(2):201-9.

34. World Health Organization. Dept. of Health S. Designing health financing systems to reduce catastrophic health expenditure. Web server without geographic relation, Web server without geographic relation (org): Geneva : World Health Organization; 2005.

35. Wang Z, Chen M, Li X. Catastrophic health expenditures and its inequality in elderly households with chronic disease patients in China. International Journal for Equity in Health. 2015;14(1).

36. Si Y, Zhou Z, Su M, Ma M, Xu Y, Heitner J. Catastrophic healthcare expenditure and its inequality for households with hypertension: Evidence from the rural areas of Shaanxi Province in China. International Journal for Equity in Health. 2017;16(1). 
37. Li Zhen. 70 years of basic medical insurance: From scratch to achieve basic full coverage of the population. Chinese Journal of Health Policy(in Chinese). 2019;12(12):1-6.

38. Yan Jue, Yan Yongliang, Hao Nina, Yang Jinjuan, Gao Jianmin, Li Qian, Wang Yaru, Lai Sha. Empirical Study on the Relief Effect of Catastrophic Health Expenditure under Three Basic Medical Schemes. Chinese Health Economics(in Chinese). 2012;31(01):26-8.

39. Lu Xuemei, Ci Qinying. The influencing factors of catastrophic health expenditure of poor families and the choice of medical assistance policy -- Based on Amartya Sen's perspective of feasible ability. Guangxi Federation of Social Sciences(in Chinese). 2017;8:152-7.

40. Li J, Jiao C, Nicholas S, Wang J, Chen G, Chang J. Impact of medical debt on the financial welfare of middle-and low-income families across china. International Journal of Environmental Research and Public Health. 2020;17(12):1-13.

41. Zhao Y, Fu Y, Zhang L, Wang M, Zhang L. Socioeconomic disparities in cancer treatment, service utilization and catastrophic health expenditure in China: A cross-sectional analysis. International Journal of Environmental Research and Public Health. 2020;17(4). 